\title{
Properties of Biodegradable Polymer from Terrestrial Mushroom for Potential Enhanced Oil Recovery
}

\author{
Tengku Amran Tengku Mohd ${ }^{1,2, *}$, Shareena Fairuz Abdul Manaf ${ }^{1}$, Munawirah Abd Naim¹, \\ Muhammad Shafiq Mat Shayuti ${ }^{1}$, and Mohd Zaidi Jaafar ${ }^{2}$
}

${ }^{1}$ Faculty of Chemical Engineering, Universiti Teknologi MARA, 40450 Shah Alam, Selangor, Malaysia

${ }^{2}$ School of Chemical and Energy Engineering, Faculty of Engineering, Universiti Teknologi Malaysia,

Skudai, 81310 Johor Bahru, Malaysia

\section{* Corresponding author:}

tel: +603-55436534

email:amran865@uitm.edu.my

Received: December 6, 2019

Accepted: May 28, 2020

DOI: $10.22146 /$ ijc. 52254

\begin{abstract}
Polymer flooding could enhance the oil recovery by increasing the viscosity of water, thus, improving the mobility control and sweep efficiency. It is essential to explore natural sources of polymer, which is biologically degradable and negligible to environmental risks. This research aims to produce a biodegradable polymer from terrestrial mushroom, analyze the properties of the polymer and investigate the oil recovery from polymer flooding. Polysaccharide biopolymer was extracted from mushroom and characterized using Fourier Transform Infrared Spectrometer (FTIR), while the polymer viscosity was investigated using an automated microviscometer. The oil recovery tests were conducted at room temperature using a sand pack model. It was found that polymer viscosity increases with increasing polymer concentration and decreases when increase in temperature, salinity, and concentration of divalent ions. The oil recovery tests showed that a higher polymer concentration of 3000 ppm had recovered more oil with an incremental recovery of $25.8 \%$ after waterflooding, while a polymer concentration of 1500 pm obtained incremental 22.2\% recovery of original oil in place (OOIP). The oil recovery from waterflooding was approximately 25.4 and $24.2 \%$ of the OOIP, respectively. Therefore, an environmentally friendly biopolymer was successfully extracted, which is potential for enhanced oil recovery (EOR) application, but it will lose its viscosity performance at certain reservoir conditions.
\end{abstract}

Keywords: biopolymer; mushroom; polymer flooding; viscosity; enhanced oil recovery

\section{- INTRODUCTION}

Enhanced oil recovery (EOR) includes the mobilitycontrol processes that favor the mobility ratio to improve sweep efficiency [1]. The thickening of water with a biopolymer and reducing gas mobility with foams are such examples. In most cases, biopolymer flooding is used in the EOR process as the thickening agent, which can improve the mobility of oil by increasing the viscosity of water. When the mobility ratio is larger than 1 , it results in instability of the flow due to less viscous solvent (water) displacing a more viscous solvent (oil), which will lead to viscous fingering. In contrast, when the mobility is less than 1 , improvement can be made by increasing the viscosity of displacing fluid and lowering the viscosity of displaced fluid [2-3]. Therefore, polymers have benefits in enhancing the viscosity of water solution, which in turn reducing the mobility ratio between water and oil, resulting in improvement of sweep efficiency [4]. Besides that, gelled polymer technology could be applied to seal high permeability zones and fractures, resulting in improving sweep efficiency and oil recovery [5]. Another chemical EOR process, which could provide mobility control, is foam flooding, involving the investigation of mobility [6], as well as the improvement of foam stability with the addition of nanoparticles [711]. These EOR processes could be monitored using a real-time approach of streaming potential measurement using electrodes permanently installed downhole, which 
is the potential to monitor alkaline-surfactant-polymer (ASP) flooding [12-13].

Polymers can be divided into two types, naturally occurred and synthetic. Synthetic polymers such as polyacrylamides are produced from the polymerization of acrylamide monomer, while naturally occurred polymers such as polysaccharides biopolymer are produced by microbial action of organisms. A biopolymer is gaining interest in the EOR process since it possesses stable characteristics at the reservoir condition and only degrades under certain conditions [3]. A biopolymer is an excellent thickening agent at high salinity water. The biopolymer degradation may occur by loss of solution viscosity with time. As a thickening agent, the pivotal feature of the biopolymer is water-soluble. The concentration of the biopolymer solution is dependent on the salinity and the temperature of the reservoir itself. Mohd et al. demonstrated that the properties of several synthetic and natural polymers such as partial-hydrolyzed polyacrylamide (HPAM), polyvinylpyrrolidone, xanthan gum, guar gum, and Arabic gum change significantly with shear rate, polymer concentration, temperature, salinity and divalent ions [14]. Shear thickening and thinning occur at high and low fluid velocities in porous media, respectively. Further increase in velocity could result in polymer degradation due to the rupture of the polymer chain [15]. Hence, optimal polymer rheological properties are important for the polymer flooding process to obtain high oil recovery [16].

Polymer stability is important for polymer flooding. However, some polymers are thermally degraded at high temperature reservoir. Thermal degradation can be accelerated by the presence of dissolved oxygen and iron in the brine. Interestingly, thermal degradation can be reduced by using additives, especially oxygen scavenger [17]. It helps the polymer to remain stable in the reservoir from degradation. From the previous study on polymer concentration, a high salinity reservoir needs a high concentration of polymer for the great efficiency of displacing fluid in the reservoir. Polymers from natural sources have been selected because the raw materials are in abundance, readily available, easy to handle, environmentally friendly, and biodegradable. Their rigid structure and long polysaccharides chains make them suitable to withstand the harsh reservoir conditions. The natural polymers that have been investigated for EOR application at laboratory scale are mushroom and cabbage [18]; Saccharomyces cerevisiae [19]; okra [20]; cassava starch [21]; Detarium microcarpum [22]; gum Arabic [23]; Irvingia gabonensis [21,24]; Brachystegia eurycoma [24]; exudate gum [25]; aqueous beans [26] and schizophyllan [27].

However, many synthetic polymers are not biologically degradable, which become threats to some countries. It is essential to explore the natural source of a biopolymer, which is stable at reservoir environment and potential in the EOR application. Terrestrial mushroom has a great potential for a source of biopolymer, which was investigated in this study for potential applications in polymer flooding. Thus, this paper emphasizes the extraction process of biopolymer from the mushroom, analysis of its properties at various reservoir conditions, and determination of oil recovery from polymer flooding.

\section{- EXPERIMENTAL SECTION}

\section{Materials}

The material used to produce a polysaccharide biopolymer is the local terrestrial mushrooms. For extraction of polysaccharides, the chemicals used were methanol and ethanol purchased from Merck, sodium hydroxide $(\mathrm{NaOH})$ obtained from Sigma-Aldrich, and distilled water. Other chemicals were sodium chloride $(\mathrm{NaCl})$, calcium chloride $\left(\mathrm{CaCl}_{2}\right)$, and magnesium chloride $\left(\mathrm{MgCl}_{2}\right)$ from $\mathrm{Vchem}$ used as brine and divalent salts, respectively, for polymer properties measurement, while paraffin oil obtained from Sigma-Aldrich was used for polymer flooding in porous media using sand pack model. Silica sand was obtained from the sea sand at the Pantai Port Dickson, sieved at desired sizes ranging from 150 to $250 \mu \mathrm{m}$ and purified.

\section{Procedure}

\section{Extraction of mushroom polysaccharide}

Freeze-dried mushrooms (1 g) were initially extracted with methanol at $65^{\circ} \mathrm{C}$ for $8 \mathrm{~h}$ to remove soluble 
molecules, such as lipids, soluble sugars, or phenolic compounds. Subsequently, polysaccharide extraction was carried out in $30 \mathrm{~mL}$ water at room temperature for $24 \mathrm{~h}$ prior to separation. The solid was separated by centrifugation at $4{ }^{\circ} \mathrm{C}$ for $4000 \mathrm{rpm}$. The residue was reextracted with $30 \mathrm{~mL}$ of water at $80{ }^{\circ} \mathrm{C}$ for $24 \mathrm{~h}$. The extract was centrifuged as a similar previous condition to obtain the solid residue. The remaining solid was added with $30 \mathrm{~mL}$ of $1 \mathrm{M} \mathrm{NaOH}$ and placed in an oven at $80^{\circ} \mathrm{C}$ for $24 \mathrm{~h}$ and re-centrifuged. The liquids from each extraction process were precipitated separately by adding ethanol in 2:1 ratio (v/v), and the resulting polysaccharide extracts were re-dissolved in distilled water.

\section{Fourier transform infrared spectroscopy (FTIR) analysis}

The FTIR spectra of the extracted polysaccharides were collected by using a Nicolet 6700 FTIR spectrophotometer (Thermo Fisher Scientific, USA). Each sample was scanned in FTIR spectra from 4000 to $400 \mathrm{~cm}^{-1}$ with a detector at $2 \mathrm{~cm}^{-1}$ resolution.

\section{Properties of mushroom polysaccharide}

The polymer was tested using AMVn Automated Micro Viscometer (Anton Paar). The polymer was filled in the capillary tube and inserted into the capillaries of the capillary block. By using the AMVn system, the viscosity reading was recorded four times, and then the average reading was taken. Polymer viscosity was investigated with respect to polymer concentration, temperature, salinity, and concentration of divalent salts. For analysis of polymer concentration, the polymer was investigated in the range of 500 to $5000 \mathrm{ppm}$, while the temperature effect was analyzed from 15 to $85^{\circ} \mathrm{C}$. The effect of salinity was investigated using sodium chloride $(\mathrm{NaCl})$, ranging from 1000 to $10000 \mathrm{ppm}$. The same concentration ranges were applied for divalent ion concentration analysis using calcium chloride $\left(\mathrm{CaCl}_{2}\right)$ and magnesium chloride $\left(\mathrm{MgCl}_{2}\right)$. The viscosity readings recorded were analyzed and plotted against the respective parameter.

\section{Displacement tests for enhanced oil recovery}

The recovery tests were conducted at room temperature of $25^{\circ} \mathrm{C}$. The sand pack model was prepared and packed with local sand homogeneously of sizes ranging

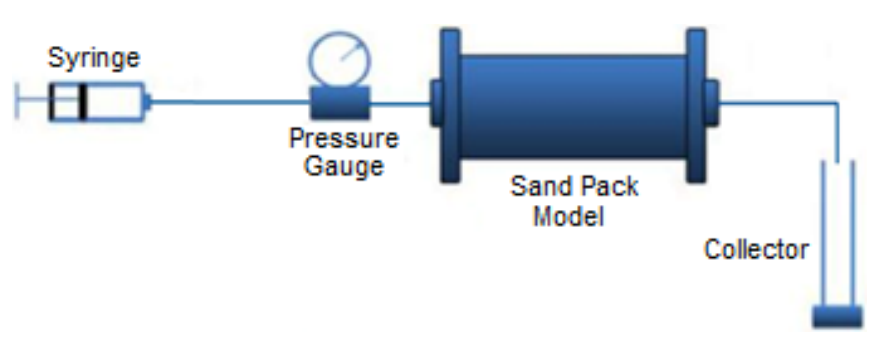

Fig 1. Displacement test set-up

from 150 to $250 \mu \mathrm{m}$. The porosity and permeability of the sand pack model obtained were 0.394 and 4.7 darcy, respectively, with a pore volume (PV) of $29.7 \mathrm{~cm}^{3}$. The flooding tests were conducted in a horizontal orientation as the experimental set-up shown in Fig. 1. The sand pack was saturated with $1.0 \mathrm{wt} . \%$ brine solution, and then paraffin oil was injected continuously, displacing the brine to initiate the initial reservoir condition. After that, brine was injected at approximately $1 \mathrm{cc} / \mathrm{min}$ as a secondary recovery waterflooding process. The brine injection was stopped when the water breakthrough started to occur, and no more oil could be recovered in the process. The volume of oil recovered in the collector was recorded. After that, the co-injection of the polymer was conducted into the sand pack. The injection rate for polymer solution was fixed at $0.5 \mathrm{cc} / \mathrm{min}$, and the volume of oil displaced was recorded at each $0.2 \mathrm{PV}$ of polymer solution injected into the sand pack. The sand pack was cleaned by using methyl alcohol before proceeding with another run of flooding tests.

\section{- RESULTS AND DISCUSSION}

\section{Extraction of Mushroom Polysaccharide}

A terrestrial edible mushroom was used to produce a polymer solution for this study. Three methods were carried out for the extraction of polysaccharides. The first extraction, which was conducted with water at room temperature, yielded a very low purity of polysaccharide while, the extraction from water and $\mathrm{NaOH}$ at $80{ }^{\circ} \mathrm{C}$, yielded more pure polysaccharides [28]. The purity of the obtained polysaccharides can be clearly seen from its color beside FTIR analysis to check the functional group of polysaccharides. Fig. 2 shows the polymer produced from the three extractions, a) water at room temperature, b) water at $80^{\circ} \mathrm{C}$, and c) $1 \mathrm{M} \mathrm{NaOH}$ at $80^{\circ} \mathrm{C}$, respectively. 


\section{FTIR Analysis}

FTIR analysis was conducted to determine the functional group of polysaccharides from the samples, as given in Fig. 3. From all three conditions tested, it was clearly observed that the same functional group has demonstrated a similar pattern with several peaks [29-30].

The presence of functional groups such as $\mathrm{O}-\mathrm{H}$ stretch (wavelength between 3300-3400 $\mathrm{cm}^{-1}$ ), $\mathrm{C}=\mathrm{O}$ stretch (wavelength between 1544-1652 $\mathrm{cm}^{-1}$ ), and $\mathrm{C}-\mathrm{O}$ stretch (wavelength of $1048 \mathrm{~cm}^{-1}$ ) were observed from FTIR as given in Fig. 3, which are belongs to polymer compounds. Hence, it demonstrated that the extraction of polysaccharide in this study has been successful.

\section{Properties of Mushroom Polysaccharide}

Viscosity measurement was conducted to analyze the properties of the polymer at various conditions. In this

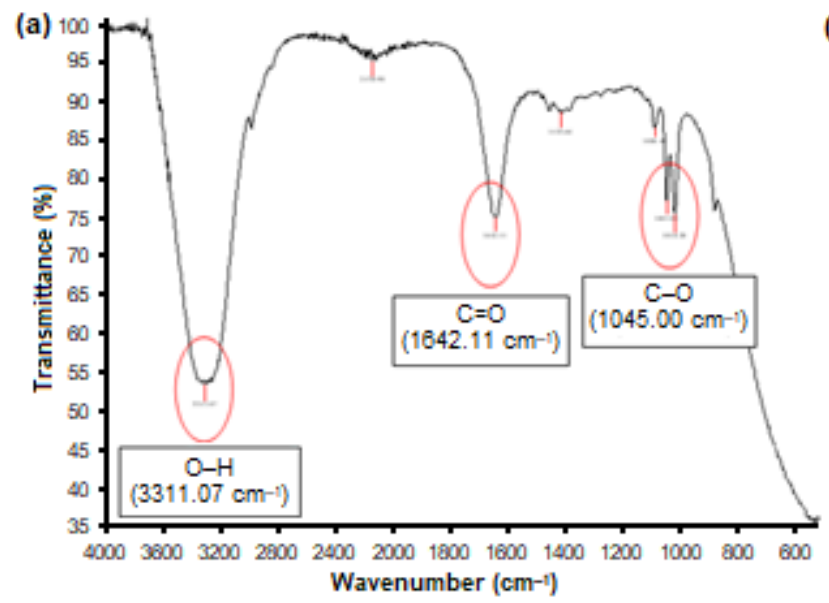

study, the viscosity was investigated at various polymer concentrations, temperature, brine concentration, and divalent ions concentration, as shown in Fig. 4.

\section{Polymer concentration}

Fig. 4(a) clearly showed that by raising the polymer concentration has increased the viscosity. The polymer was unstable at lower concentrations due to low viscosity. At $1000 \mathrm{ppm}$, the polymer started to show stability where the viscosity reading is high at approximately $12.3 \mathrm{cP}$ and

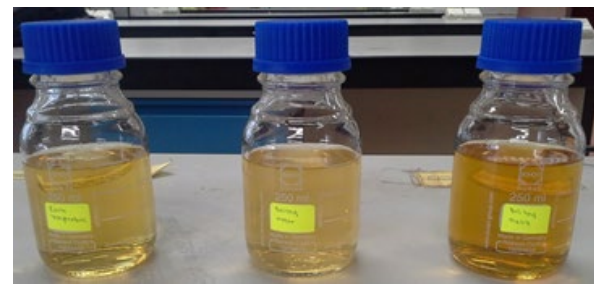

Fig 2. Polysaccharides biopolymer extracted from the mushroom

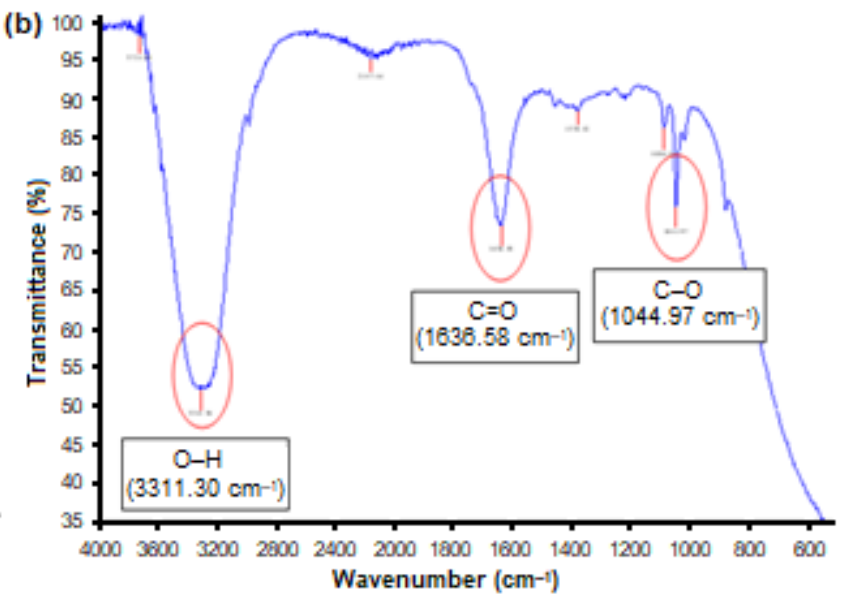

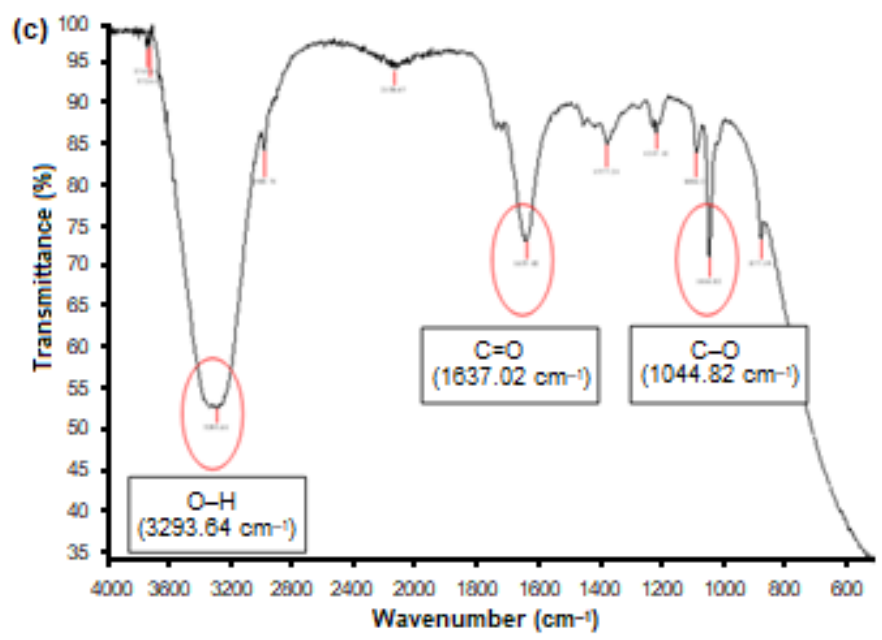

Fig 3. FTIR analysis of sample extracted with (a) water at room temperature, (b) water at $80^{\circ} \mathrm{C}$, (c) $1 \mathrm{M} \mathrm{NaOH}$ at $80^{\circ} \mathrm{C}$ 

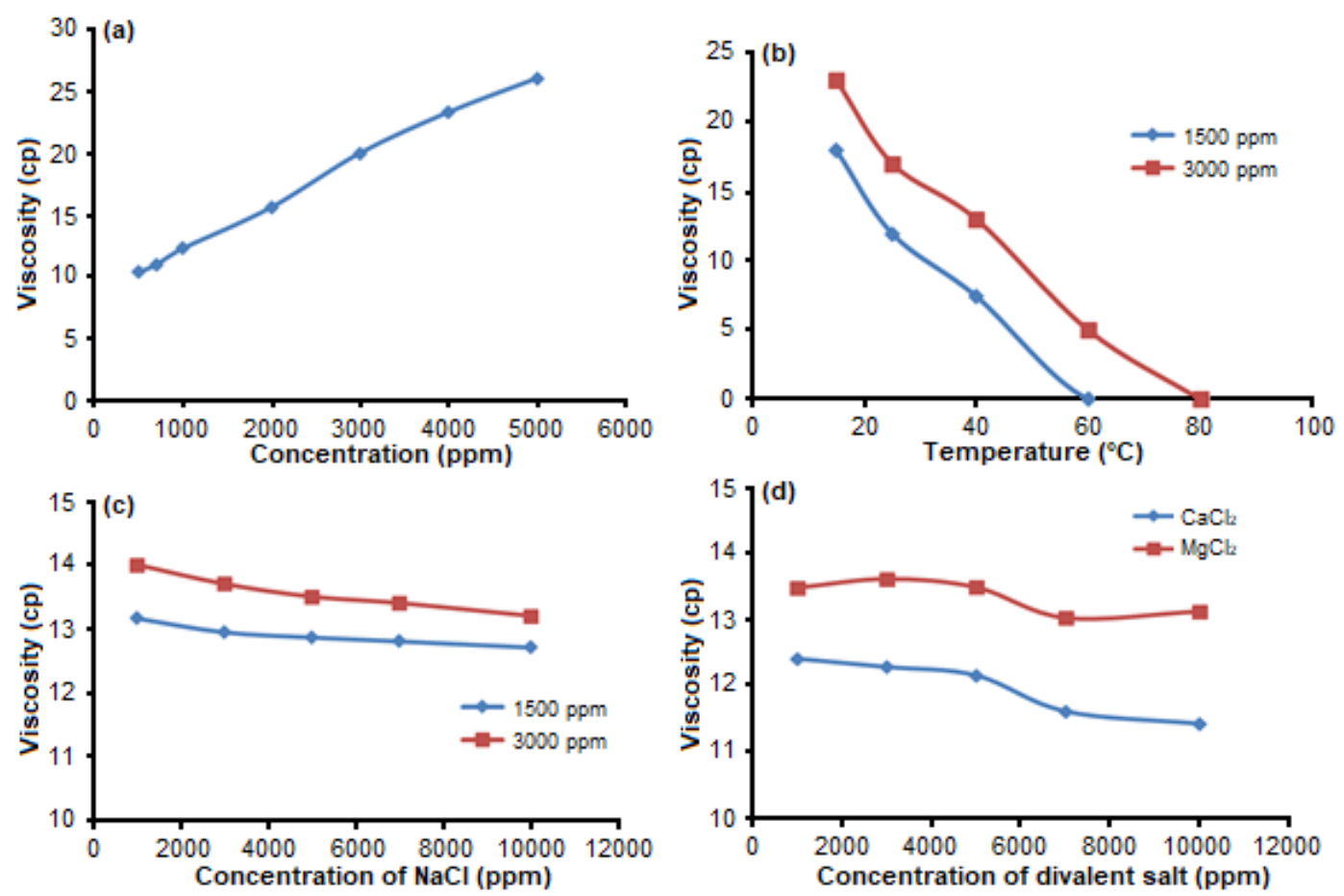

Fig 4. The polymer viscosity at various (a) polymer concentration (ppm), (b) temperature $\left({ }^{\circ} \mathrm{C}\right),(\mathrm{c})$ brine concentration (ppm), (d) divalent ion concentration (ppm)

kept increasing with increase in the polymer concentration. Like other polysaccharides, the viscosity of this extracted biopolymer increases with increasing polymer concentration [31]. The highest polymer viscosity of about $26 \mathrm{cP}$ was obtained at the highest polymer concentration investigated at $5000 \mathrm{ppm}$. As a polysaccharide, this biopolymer can behave as a nonNewtonian and pseudoplastic fluid, exhibiting shearthinning behavior like other polysaccharide biopolymers such as Brachystigia eurycoma and Irvingia gabonensis [24,32] and aqueous beans [26]. From the previous study, a higher concentration of polymer, which could provide higher viscosity is required to recover more oil from the reservoir, as the mobility ratio between the displacing fluid to the displaced fluid is more favorable, resulting in improvement of sweep efficiency [33]. Moreover, a high concentration of polymer can withstand high temperatures and salinity reservoir environments $[3,34]$.

\section{Temperature}

Fig. 4(b) shows the results of the temperature effect on the viscosity of extracted biopolymer at 1500 and 3000 ppm. Polymer at 1500 ppm concentration degraded earlier than that at $3000 \mathrm{ppm}$ concentration. In addition, the $3000 \mathrm{ppm}$ polymer can withstand higher temperature up to $80^{\circ} \mathrm{C}$ before it was fully degraded, compared to $1500 \mathrm{ppm}$ polymer, which was completely degraded at $60{ }^{\circ} \mathrm{C}$. Viscosity reduction is due to the stronger thermal vibration of water molecules that retard the association effect at high temperatures [4]. Thus, this extracted biopolymer is most applicable at low temperature like xanthan biopolymers, which are mostly limited to applications where the temperature is lower than $60{ }^{\circ} \mathrm{C}$ [3]. However, the polymer is likely unstable and immature to react at low temperature, while at high reservoir temperature, the polymer loses its viscosity and degrades [35]. This situation shows that very high polymer concentration is required at high-temperature reservoir conditions to minimize the loss of its viscosity efficiency.

\section{Salinity}

Generally, the addition of salt affects the viscosity of the polymer solution. When the salinity is high, the polymer performance decreases as it losses its viscosity. Most of the reservoir is in high salinity condition. Hence, a suitable polymer concentration is important to prevent 
viscosity reduction [3]. Based on the test conducted, the result is shown in Fig. 4(c) by using monovalent salt, $\mathrm{NaCl}$. Two concentrations of polymer were tested at 1500 and $3000 \mathrm{ppm}$. It can be seen that by increasing the concentration of $\mathrm{NaCl}$, the viscosity lost its efficiency. However, the viscosity of the biopolymer is much less affected by the change in salinity compared with a synthetic polymer such as HPAM [3,14], as the viscosity of this biopolymer steadily decreases with increasing $\mathrm{NaCl}$ concentration. Small viscosity reductions of 0.8 and $0.5 \mathrm{cP}$ were observed for both 1500 and $3000 \mathrm{ppm}$ polymer concentrations, respectively, when the $\mathrm{NaCl}$ concentration increases from 1000 to $10000 \mathrm{ppm}$. A drastic viscosity reduction could occur to HPAM because when an electrolyte such as $\mathrm{NaCl}$ is added to a polymer solution, the repulsive forces are screened by a double layer of electrolytes, and the extension is reduced. As the electrolyte concentration increases, the extension of the polymer chain decreases, resulting in a reduction of the solution viscosity [3]. Therefore, the concentration of polymer was increased to withstand high salinity conditions much longer [34].

\section{Divalent ion}

The divalent ions are known to tightly bind the anions along the polyelectrolyte chain because they have higher charge and polarizability, causing the polymer chain to contract to its minimum size and reduce its viscosity. In this study, the extracted biopolymer was kept constant at $1500 \mathrm{ppm}$ to observe the effect at varying divalent ions $\left(\mathrm{Ca}^{2+}\right.$ or $\left.\mathrm{Mg}^{2+}\right)$. Fig. 4(d) shows the result obtained where $\mathrm{CaCl}_{2}$ results in more viscosity reduction than $\mathrm{MgCl}_{2}$ [36]. This situation is slightly similar to the salinity test using $\mathrm{NaCl}$ as a monovalent ion effect on viscosity. It was found that the divalent ion contents do not have much effect on the viscosity of biopolymer compared with HPAM [3]. Still, the viscosity reduction is larger than the monovalent ion effect. Therefore, this can be overcome by adding a high concentration of polymer since, in reality, the reservoir is in high salinity condition [33].

\section{Displacement Test for Enhanced Oil Recovery}

The test on oil recovery was conducted to determine the percentage of oil recovered from waterflooding, and the incremental oil recovery yielded from polymer flooding. The experiments were performed at room temperature using a sand pack model, as shown in Fig. 1 with different polymer concentrations. Polymer solutions at 1500 and $3000 \mathrm{ppm}$ were prepared to represent low and high polymer concentrations, which were injected into the porous sand pack model to recover the oil. Basically, the higher polymer concentration could provide higher viscosity, resulting in the improvement of sweep efficiency [17]. Fig. 5 and 6 illustrate the results of oil recovery from the displacement test of waterflooding and polymer injection. It was found that polymer could further recover the residual oil, which could not be produced from waterflooding. From Fig. 5, oil recovery from the waterflooding process was approximately 25.4 and $24.2 \%$ of the original oil in place (OOIP) for the cases of 3000 and $1500 \mathrm{ppm}$ polymer concentrations, respectively. Water was injected about $2 \mathrm{PVs}$ to ensure that the oil has been fully recovered, and no more oil was produced in the collector. This could minimize the capillary end effects that might exist [37]. After that, the co-injection of the polymer was conducted, resulting in significant incremental oil recovery obtained after the waterflooding process. The percentage of oil recovered also increased with higher polymer concentration. Polymer injection at $3000 \mathrm{ppm}$ has yielded the higher

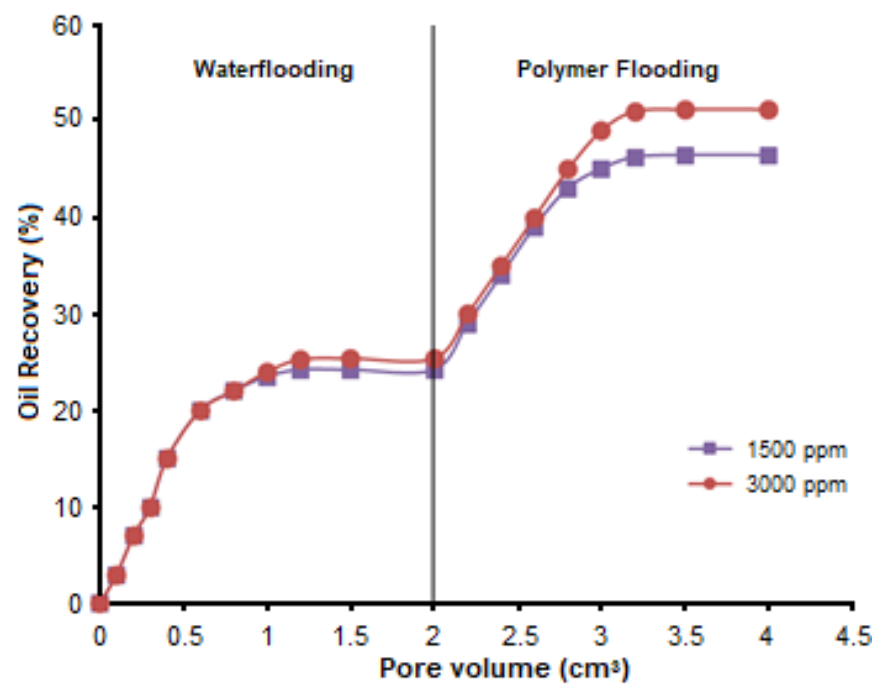

Fig 5. Oil recovery from waterflooding and co-injection of polymer 


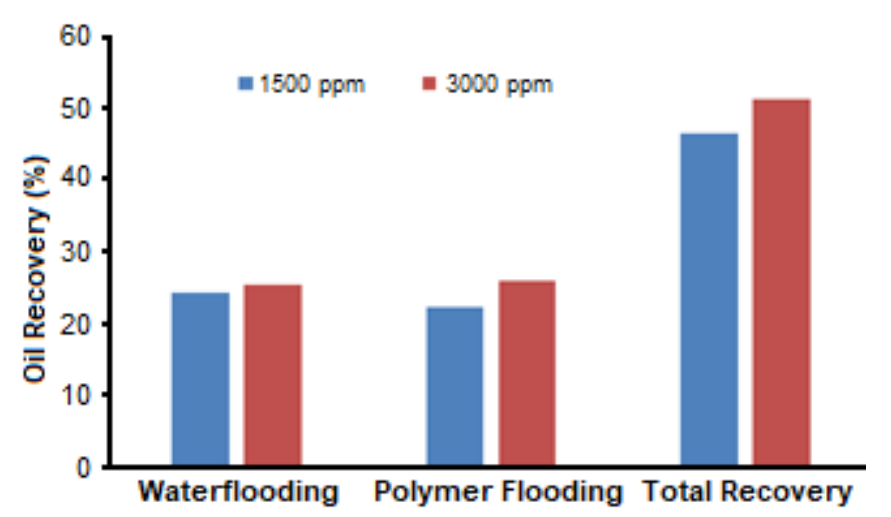

Fig 6. Oil recovery from waterflooding and polymer flooding at different polymer concentrations

incremental oil recovery of $25.8 \%$, while $1500 \mathrm{ppm}$ polymer has produced approximately $22.2 \%$ of OOIP, obtained after $2 \mathrm{PVs}$ of polymer injection. These resulted in total recoveries of 51.2 and $46.4 \%$ of OOIP, respectively, as shown in Fig. 6. These findings are comparable and supported by biopolymer flooding conducted by Ihebuzor and Onyenkonwu using okra, gum Arabic, and Irvingia gabonensis with maximum recoveries of 63.16, 53.01, and $47.37 \%$ of OOIP, respectively [32]. Also, Gbonhinbor and Onyekonwu obtained an oil recovery of $44.6 \%$ using aqueous beans [26], while Goa found an oil recovery of $55 \%$ from schizophyllan biopolymer [27]. When waterflooding is no more effective to recover the trapped oil, subsequent polymer flooding could favor the mobility ratio between the displaced fluid and the displacing fluid compared to the waterflooding, thus improving the sweep efficiency and the cumulative oil recovery. Polymer flooding can improve the macroscopic and microscopic displacement efficiency to enhance oil recovery [38]. Besides reducing the relative permeability within the porous media, the polymer acts in thickening the water, therefore reducing the mobility and minimizes the viscous fingering effect [39]. Reducing the relative permeability of water could also achieve lower mobility through the formation of a layer on the pore walls by the adsorbed polymer, flow pathway segregation of oil and water, wettability alteration, and swelling/shrinkage of the polymer depending on the phase flow. Based on the results, the higher polymer concentration results in a higher viscosity of water, which improves the mobility ratio between the displaced fluid and the displacing fluid, thus minimizing the viscous fingering, improving the sweep efficiency, and enhancing the oil recovery. The introduction of polymer flooding after waterflooding could further recover the residual oil leading to incremental oil recovery [39-40].

\section{- CONCLUSION}

From this research, it can be concluded that polysaccharides biopolymer have been successfully extracted from terrestrial mushroom, where higher purity polysaccharides were yielded from water and sodium hydroxide extraction at $80{ }^{\circ} \mathrm{C}$. In the EOR application, high viscosity polymer is required for a more favorable mobility ratio and improved sweep efficiency. It was found that the viscosity of extracted polymer increased with increasing polymer concentration and decreased with an increase in temperature. The viscosity of the biopolymer was not much affected by the change in salinity and divalent ions compared with a synthetic polymer. However, the presence of divalent ions $\left(\mathrm{Ca}^{2+}\right.$ and $\left.\mathrm{Mg}^{2+}\right)$ have further reduced the polymer viscosity compared to monovalent ion $\left(\mathrm{Na}^{+}\right)$, while $\mathrm{Ca}^{2+}$ provided a more significant reduction effect on polymer viscosity than the $\mathrm{Mg}^{2+}$. The oil recovery tests showed that polymers at a higher concentration of $3000 \mathrm{ppm}$ have recovered more oil with the incremental recovery of $25.8 \%$ after waterflooding, while $1500 \mathrm{ppm}$ polymer yielded lower oil recovery with incremental $22.2 \%$ of OOIP. The oil recovery from waterflooding was approximately 25.4 and $24.2 \%$ of the OOIP, respectively. Therefore, an environmentally friendly biopolymer was successfully extracted, which is potential for enhanced oil recovery (EOR) application, but it will lose its viscosity performance at certain reservoir conditions.

\section{- ACKNOWLEDGMENTS}

This work was financially supported by the Fundamental Research Grant Scheme (FRGS) (600IRMI/FRGS 5/3 (192/2019)) from the Ministry of Higher Education (MoHE) given to Universiti Teknologi MARA (UiTM). 


\section{- REFERENCES}

[1] Bataweel, M.A., and Nasr-El-Din, H.A., 2012, Rheological study for surfactant-polymer and novel alkali-surfactant-polymer solutions, North Africa Technical Conference and Exhibition, Cairo, Egypt, 20-22 February 2012.

[2] Seright, R., 2010, Potential for polymer flooding reservoirs with viscous oils, SPE Reservoir Eval. Eng., 13 (04), 730-740.

[3] Green, D.W., and Willhite, G.P., 1998, Enhanced Oil Recovery, SPE Textbook Series, Volume 6, Society of Petroleum Engineers, Richardson, Texas.

[4] Niu, Y., Jian, O., Zhu, Z., Wang, G., Sun, G., and Shi, L., 2001, Research on hydrophobically associating water soluble polymer used for EOR, SPE International Symposium on Oilfield Chemistry, Houston, Texas, 13-16 February 2001.

[5] Achim, N., Alias, N.H., Ghazali, N.A., Rodhi, M.N.M, Mohd, T.A.T., and Yahya, E., 2015, Polymer gelled technology to improve sweep efficiency in enhanced oil recovery: A literature review, $A d v$. Mater. Res., 1113, 690-694.

[6] Mohd, T.A.T., Alias, N., Ghazali, N.A., Yahya, E., Sauki, A., Azizi, A., and Yusof, N.M., 2015, Mobility investigation of nanoparticle-stabilized carbon dioxide foam for enhanced oil recovery (EOR), $A d v$. Mater. Res., 1119, 90-95.

[7] Mohd, T.A.T., Shukor, M.A., Ghazali, N.A., Alias, N., Yahya, E., Azizi, A., Shahruddin, M.Z., and Ramlee, N.A., 2014, Relationship between foamability and nanoparticle concentration of carbon dioxide $\left(\mathrm{CO}_{2}\right)$ foam for enhanced oil recovery (EOR), Appl. Mech. Mater., 548-549, 67-71.

[8] Azizi, A., Husin, H., Ghazali, N.A., Khairudin, M.K., Sauki, A., Alias, N.H., and Mohd, T.A.T., 2015, Nanoparticles stabilized carbon dioxide foams in sandstone and limestone reservoir, Adv. Mater. Res., 1119, 170-174.

[9] Mohd, T.A.T., Bakar, N.F.A., Awang, N., and Talib, A.A., 2018, Aqueous foams stabilized with silica nanoparticle and alpha olefin sulfonates surfactant, $J$. Mech. Eng. Sci., 12 (3), 3759-3770.
[10] Azmi, N.S.M., Roslina, N.R., Mohd, T.A.T., Tan, H.L., and Bakar, N.F.A., 2019, Diffusion coefficient and interfacial tension with addition of silica nanoparticles in $\mathrm{CO}_{2}$-surfactant-water-hexane for enhanced oil recovery (EOR) using molecular dynamic simulation, Key Eng. Mater., 797, 375-384.

[11] Azmi, N.S.M., Bakar, N.F.A., Mohd, T.A.T., and Azizi, A., 2020, Molecular dynamics simulation on $\mathrm{CO}_{2}$ foam system with addition of $\mathrm{SiO}_{2}$ nanoparticles at various sodium dodecyl sulfate (SDS) concentrations and elevated temperatures for enhanced oil recovery (EOR) application, Comput. Mater. Sci., 184, 109937.

[12] Mohd, T.A.T., Jaafar, M.Z., Rasol, A.A.A., and Ali, J., 2017, Review: A new prospect of streaming potential measurement in alkaline-surfactantpolymer flooding, Chem. Eng. Trans., 56, 11831188.

[13] Mohd, T.A.T., Jaafar, M.Z., Rasol, A.A.A., and Hamid, M.F., 2017, Measurement of streaming potential in downhole application: An insight for enhanced oil recovery monitoring, MATEC Web Conf., 87, 03002.

[14] Mohd, T.A.T., Taib, N.M., Adzmi, A.F., Ab Lah, N.K.I.N., Sauki, A., and Jaafar, M.Z., 2018, Evaluation of polymer properties for potential selection in enhanced oil recovery, Chem. Eng. Trans., 65, 343-348.

[15] Al Hashmi, A.R., Al Maamari, R.S., Al Shabibi, I.S., Mansoor, A.M., Zaitoun, A., and Al Sharji, H.H., 2013, Rheology and mechanical degradation of high-molecular-weight partially hydrolyzed polyacrylamide during flow through capillaries, $J$. Pet. Sci. Eng., 105, 100-106.

[16] Zhao, H., Luo, F., Hou, J., Zhang, X., and Cao, L., 2010, Study on the potential risk appraisal method in polymer flooding, SPE Hydrocarbon Economics and Evaluation Symposium, Dallas, Texas, USA, 8-9 March 2010.

[17] Kaminsky, R.D., Wattenbarger, R.C., Szafranski, R.C., and Coutee, A., 2007, Guidelines for polymer flooding evaluation and development, International 
Petroleum Technology Conference, Dubai, U.A.E., 4-6 December 2007.

[18] Alias, N.H., Zulkifli, M.S., Manaf, S.F.A., Yahya, E., Ghazali, N.A., and Mohd, T.A.T., 2014, Saccharomyces cerevisiae from baker's yeast for lower oil viscosity and beneficial metabolite to improve oil recovery: An overview, Appl. Mech. Mater., 625, 522525.

[19] Yahya, E., Alias, N.H., Mohd, T.A.T., Ghazali, N.A., and Ariffin, T.S.T., 2015, Flooding with biopolymer from microbes derived from mushroom and cabbage to enhance sweep efficiency in enhanced oil recovery, Adv. Mater. Res., 1113, 492-497.

[20] Ojo, V.O., Onyekonwu, M.O., Ogolo, N.A., and Ubani, C., 2013, Effect of viscosity of alkaline/surfactant/polymer on enhanced oil recovery in heterogenous sands, SPE Nigeria Annual International Conference and Exhibition, Lagos, Nigeria, 5-7 August 2013.

[21] Ikeagwu, C., and Samuel, A., 2015, The study of local polymers on enhanced oil recovery, Arch. Appl. Sci. Res., 7 (6), 48-55.

[22] Osuji, C., and Onyenkonwu, M., 2012, Using alkaline-surfactant-polymer to improve oil recovery, Thesis, Department of Petroleum and Gas, University of Port Harcourt, Nigeria.

[23] Ade, E., and Onyekonwu, M.O., 2012, Experimental study of enhancing oil recovery using local polymers, Thesis, Department of Petroleum and Gas, University of Port Harcourt, Nigeria.

[24] Ogolo, N.A., Ogiriki, S., Onyiri, V., Nwosu, T., and Onyenkonwu, M.O., 2015, Performance of foreign and local agents for enhanced oil recovery of Nigerian crude, SPE Nigeria Annual International Conference and Exhibition, Lagos, Nigeria, 4-6 August 2015.

[25] Ajabuego, I., and Onyekonwu, M., 2012, Enhanced oil recovery using local polymer, Thesis, Department of Petroleum and Gas, University of Port Harcourt, Nigeria.

[26] Gbonhinbor, J.R., and Onyekonwu, M.O., 2015, Experimental and simulation study on aqueous protein to improve oil recovery, Int. J. Pet. Eng., 1 (4), 271-289.
[27] Gao, C., 2016, Application of a novel biopolymer to enhance oil recovery, J. Pet. Explor. Prod. Technol., 6 (4), 749-753.

[28] Villares, A., García-Lafuente, A., Guillamón, E., and Mateo-Vivaracho, L., 2013, Separation and characterization of the structural features of macromolecular carbohydrates from wild edible mushrooms, Bioact. Carbohydr. Dietary Fibre, 2 (1), 15-21.

[29] Cumpstey, I., 2013, Chemical modification of polysaccharides, ISRN Org. Chem., 2013, 417672.

[30] Yadav, H., and Karthikeyan, C., 2019, "Natural polysaccharides: Structural features and properties" in Polysaccharide Carriers for Drug Delivery, Eds. Maiti, S., and Jana, S., Woodhead Publishing, Cambridge, UK.

[31] Ndjouenkeu, R., Goycoolea, F.M., Morrisa, E.R., and Akingbala, J.O., 1995, Rheology of okra (Hibiscus esculentus L.) and dika nut (Irvingia gabonesis) polysaccharides, Carbohydr. Polym., 29 (3), 263-269.

[32] Ihebuzor, N., Onyenkonwu, M.O., 2012, An experimental research on enhanced oil recovery using local polymers, Thesis, University of Port Harcourt, Nigeria.

[33] Ayirala, S.C., Uehara-Nagamine, E., Matzakos, A.N., Chin, R.W., Doe, P.H., and van den Hoek, P.J., 2010, A designer water process for offshore low salinity and polymer flooding applications, SPE Improved Oil Recovery Symposium, Tulsa, Oklahoma, USA, 24-28 April 2010.

[34] Algharaib, M.K., Alajmi, A.F.F., and Gharbi, R., 2011, Enhancing recovery in high salinity oil reservoirs through optimized polymer flood, International Petroleum Technology Conference, Bangkok, Thailand, 15-17 November 2011.

[35] Yang, F., Wang, D., Wang, G., Sui, X., Liu, W., and Kan, C., 2006, Study on high-concentration polymer flooding to further enhance oil recovery, SPE Annual Technical Conference and Exhibition, San Antonio, Texas, USA, 24-27 September 2006.

[36] Ward, J.S., and Martin, F.D., 1981, Prediction of viscosity for partially hydrolyzed polyacrylamide 
solutions in the presence of calcium and magnesium ions, SPE J., 21 (05), 623-631.

[37] Al Yousef, Z.A., Almobarky, M.A., and Schechter, D.S., 2019, Surfactant and a mixture of surfactant and nanoparticles to stabilize $\mathrm{CO}_{2} /$ brine foam, control gas mobility, and enhance oil recovery, J. Pet. Explor. Prod. Technol., 10 (2), 439-445.

[38] Romero-Zeron, L., 2012, "Advances in enhanced oil recovery" in Introduction to Enhanced Oil Recovery (EOR) Process and Bioremediation of Oil Contaminants Sites, Eds. Romero-Zeron, L.,
IntechOpen, Rijeka.

[39] Kotlar, H.K., Selle, O., and Torsaeter, O., 2007, Enhanced oil recovery by COMB flow: Polymer floods revitalized, International Symposium on Oilfield Chemistry, Houston, Texas, USA, 28 February-2 March 2007.

[40] Agi, A., Junin, R., Gbonhinbor, J., and Onyekonwu, M., 2018, Natural polymer flow behaviour in porous media for enhanced oil recovery applications: A review, J. Pet. Explor. Prod. Technol., 8 (4), 1349-1362. 